\title{
The Value of a Systematic Protocol Using Endobronchial Ultrasound and Endoscopic Ultrasound in Staging of Lung Cancer for Patients with Imaging iNO-N1 Disease
}

\author{
Rosa Cordovilla ${ }^{a}$ Marco López-Zubizarreta ${ }^{a}$ Antonio Velasco $^{b}$ \\ Alberto Álvarez ${ }^{\mathrm{b}}$ Marta Rodríguez ${ }^{\mathrm{c}}$ Asunción Gómez ${ }^{\mathrm{c}}$ \\ Miguel Ángel Hernández-Mezquita ${ }^{a}$ Miguel Iglesias $^{a}$ \\ anterventional Pulmonology Unit, Pulmonary Department, Salamanca University Hospital, Salamanca, Spain; \\ ${ }^{\mathrm{b}}$ Gastroenterologist Department, Salamanca University Hospital, Salamanca, Spain; ' Cytopathology Unit, Pathology \\ Department, Salamanca University Hospital, Salamanca, Spain
}

\section{Keywords}

Endobronchial ultrasound · Endoscopic ultrasound ·

Staging · Lung cancer $\cdot$ Radiographically normal mediastinum

\begin{abstract}
Introduction: We hypothesize that systematic, combined, and multidisciplinary study of the mediastinum (endobronchial ultrasound [EBUS] and endoscopic ultrasound [EUS]) in patients with NSCLC with radiologically normal mediastinum improves the results of mediastinal staging obtained with EBUS alone. Material and Methods: A retrospective study of the prospective database collected on the patients with NSCLC with a radiologically normal mediastinum and an indication for systematic staging with EBUS and EUS. EBUS staging was followed by EUS in patients in which the results from the pathological analysis of EBUS were negative. Results: Forty-five patients were included in the analysis. The combination of EBUS followed by EUS provided better results than EBUS alone: sensitivity (S) 95\% versus $80 \%$, negative predictive value (NPV) $96.15 \%$ versus $86.21 \%$, negative likelihood ratio 0.05 versus 0.20 , and post-test probability
\end{abstract}

$3.8 \%$ versus $13.8 \%$. This represents an increase in $S(15 \%)$, the validity index $(6.6 \%)$, and NPV (9.9\%) compared to EBUS alone. There were 4 false negatives (FNs) (8.8\%) with the EBUS test alone. After adding EUS, 3 more cases were positive (6.6\%) and only $1 \mathrm{FN}(2.2 \%)$. Conclusions: In patients with NSCLC and a radiographically normal mediastinum, a systematic and combined staging with EBUS and EUS show higher sensitivity in the detection of mediastinal metastasis than with the use of EBUS alone. The high accuracy of the test means that the use of mediastinoscopy is not necessary to confirm the results in these patients. Since the availability of EUS is low, it may be advisable for the interventional pulmonologist to receive training in EUS-b.

$$
\begin{aligned}
& \text { (c) } 2021 \text { The Author(s). } \\
& \text { Published by S. Karger AG, Basel }
\end{aligned}
$$

\section{Introduction}

Accurate staging is essential in lung cancer management. Both the treatment and prognosis depend not only on its histological type but also on the stage of the disease [1-3]. karger@karger.com www.karger.com/bmh

Karger $\stackrel{\text { ' }}{=}$

BOPEN ACCESS
(C) 2021 The Author(s)

Published by S. Karger AG, Basel

This is an Open Access article licensed under the Creative Common Attribution-NonCommercial-4.0 International License (CC BY-NC) (http://www.karger.com/Services/OpenAccessLicense), applicable to the online version of the article only. Usage and distribution for commercial purposes requires written permission. 
Imaging techniques such as thoracic computerized tomography (CT) and positron emission tomography (PET) are used as a first-line modality to rule out mediastinal and distant metastatic disease. The appearance of lymph nodes larger than $10 \mathrm{~mm}$ on the CT or PET-positive mediastinal lymph nodes or both increase the probability of metastatic disease yet the accuracy of both tests is suboptimal. Hence, tissue samples are recommended to confirm or rule out metastasis. This is applicable to both group of patients with and without mediastinal involvement on the radiographic studies, especially among those with central lesion and suspected to have N1 disease [46]. This group with $\mathrm{N} 0-\mathrm{N} 1$ disease is especially important because even with tumor $<3 \mathrm{~cm}$, we can find occult lymph node metastasis [7-9].

The clinical practice guidelines recommend sampling the mediastinum with minimally invasive techniques, such as endobronchial ultrasound (EBUS) or endoscopic ultrasound (EUS) with fine-needle aspiration, both of which show a diagnostic yield comparable to the mediastinoscopy, which remains the gold standard to date [2, 4-6]. Several meta-analyses have shown a higher yield in staging by combining EBUS and EUS as a single technique because it makes it possible to access most lymph node stations and is more sensitive in the detection of lymph node metastasis than EBUS or EUS alone (global sensitivity [S] 0.86-0.91\%) [10-15]. This increase in $S$ by combining both tests depend on the quality of the procedure [16]. Therefore, mediastinoscopy is only recommended when puncture techniques are negative and there is still a high probability of malignancy [17]. This high post-test probability of malignancy was defined by De Leyn et al. $[4,6]$ in the ESTS guidelines, and it is described as a probability of lymph node involvement over $10 \%$. Consequently, a negative predictive value (NPV) under $90 \%$ or a negative likelihood ratio (-LR) over 10 would require a mediastinoscopy after negative results with EBUS and EUS [4, 6]. However, some authors advise against mediastinoscopy in patients with a radiographically normal mediastinum even when puncture techniques are negative $[18,19]$.

Several authors use this combined technique with a single scope (EBUS + EUS-b), with a high diagnostic yield $[11,20,21]$. The disadvantage of the use of this combined technique with a single probe is the lack of training in gastrointestinal endoscopy, mainly in Spain [22].

In lung cancer patient with radiographically obvious mediastinal involvement, the diagnostic yield with the combined use of both tests has been previously demonstrate $[10-13,15]$. Systematic staging in these patients

Lung Cancer Staging by EBUS-EUS in

Normal Mediastinum with the sampling of all the lymph node stations regardless of PET with CT (PET-CT) uptake shows better results because it can detect lymph node metastases that are not detected by these imaging tests. Therefore, systematic staging is recommended for these patients, combined with EBUS and EUS $[23,24]$. However, there are only a few studies that analyze the diagnostic yield of this combined approach in patients with a radiographically normal mediastinum $[19,21,25]$. The rate of false negatives (FNs) in the group of patients with a radiographically normal mediastinum is low although more predominantly in regions that cannot be reached with EBUS [26]. However, the combined EBUS and EUS procedure is more time and resource consuming than the sum of each test performed separately [27]. Therefore, it is important to select patients with a radiographically normal mediastinum who will benefit most from this procedure.

A team approach between a gastrointestinal endoscopy and interventional bronchoscopy teams makes it possible to perform a complete examination of the mediastinum in a single procedure while preserving all guarantees regarding yield and safety. We hypothesize that the systematic, combined, and multidisciplinary assessment of the mediastinum in patients with NSCLC and a radiographically normal mediastinum (EBUS and EUS) can improve the results of staging provided by EBUS alone and should therefore be recommended as a routine procedure for this group.

\section{Objective}

Our objective was to analyze the added value of a systematic, combined, and multidisciplinary assessment with EBUS and EUS in a single procedure when compared with EBUS alone in the staging of non-small cell lung cancer in patients with a radiographically normal mediastinum.

\section{Material and Methods}

\section{Study Design}

This was a retrospective analysis of prospectively collected data from a single center that included all consecutive patients with NSCLC, who met the criteria for surgery and underwent EBUS and EUS for mediastinal staging according to current clinical practice guidelines [2, 4-6]. All patients had undergone imaging tests, chest CT, and/or PET-CT.

Mediastinal involvement was established when the patient presented lymph nodes larger than $10 \mathrm{~mm}$ and/or nodes with a standardized uptake value (SUV) over 2.5 [28]. Patients with lymph 
node involvement in CT and/or PET were excluded. Patients with a radiologically normal mediastinum were included in the study. The patient cohort was divided into different groups: patients with suspicion of N1 involvement; patients with a central tumor; patients with a peripheral tumor larger than $3 \mathrm{~cm}$, and patients with tumor with low SUV.

\section{Procedure}

The procedure was performed as an outpatient under local anesthesia and moderate sedation in the bronchoscopy room with a BFUC180 ultrasound bronchoscope (Olympus Optical Co. Ltd, Tokyo, Japan) and an Olympus UE160 ultrasound endoscope (Olympus Optical Co. Ltd). The puncture aspiration was performed with a 22G needle (NA-201XS-4022; Olympus Optical Co.) for EBUS and a 25G needle (NA-220H/8025) for EUS. The procedure was performed by an experienced pneumologist as well as gastroenterologist.

EBUS was performed first, and if the results were negative on the rapid on-site evaluation (ROSE) performed by the pathologist, the gastroenterology specialist carried out EUS [27]. A systematic examination of the ipsilateral and contralateral mediastinum was performed (stations $2,4,7,10,11,8$, and 9), together with the celiac trunk and the left suprarenal gland, and all the lymph nodes larger than $5 \mathrm{~mm}$ were aspirated, starting with N3. The stations $4 \mathrm{~L}$ and 7 were sampled via both endobronchial and esophageal ultrasound when they were observed in the 2 tests.

The ROSE determined that the sample was positive if malignant cells were observed, negative when lymphocytes were found, or inadequate when none of the previous findings were observed and the test revealed bronchial cells, necrosis, blood cells, or insufficient material for a diagnosis. The presence of malignant cells was considered a true positive since false positives with EBUS-EUS are very rare [29]. The gold standard was histology from mediastinoscopy or surgical resection in patients without $\mathrm{N} 2-\mathrm{N} 3$ involvement.

\section{Statistical Analysis}

A descriptive study was carried out with the categorical variables expressed as absolute and relative frequencies. The $\chi^{2}$ test was applied to the bivariate analysis of these variables, and the Fisher's exact test was conducted when the expected frequencies were lower than 5. In all contrasts, statistical significance was established for a $p$ value $\leq 0.05$. Continuous variables were expressed as mean value and standard deviation and their differences were calculated with the difference in means and $95 \%$ confidence interval (CI). The Student's $t$ test was used to establish the correlation between dichotomous qualitative and quantitative variables. Agreement was calculated with kappa coefficient. The validity of EBUS, EUS, and the combined tests was determined with the usual formulas. The Youden's index was also calculated for the different tests. The posttest probability was calculated with Fagan nomograms and the NNT, that is, the number of EUS procedures that had to be performed to detect one more case with lymph node metastasis that had not been previously detected by EBUS. It is the inverse of the absolute risk reduction (ARR) and we calculated the reduced risk of a FN result with combined EBUS and EUS compared to EBUS alone.

The statistical analysis and processing of data were carried out with the Statistical Package for Social Sciences (SPSS) v. 23. In some of the procedures, the programs Epidat 3.1 and Epidat 4.2 were also used.

\section{Results}

Between June 2012 and September 2018, 293 patients underwent noninvasive staging for suspected NSCLC of the lung. In all cases, EBUS and EUS were indicated for the staging. Two hundred and twenty-three patients were excluded because they showed mediastinal involvement on the imaging tests. Out of the remaining 70 patients, 25 were excluded because EUS was not available for staging (35.7\%). Therefore, finally, 45 patients with a radiologically normal mediastinum were analyzed (shown in Fig. 1). The patients with suspicion of N1 involvement were $23(51.1 \%)$; patients with a central tumor: $15(33.3 \%)$; patients with a peripheral tumor larger than $3 \mathrm{~cm}$ : 5 (11.1\%); and patients with low SUV: 2 (4.5\%).

Out of the 45 patients with average age of $67.9 \pm 8.7$ years, 39 were men $(86.7 \%)$. Gender and age showed no influence on the rate of mediastinal involvement $(p=$ 0.5563 and $p=0.2580$, respectively) (Table 1 ).

In 16 patients (35.6\%), EBUS was positive for $\mathrm{N} 2$ or $\mathrm{N} 3$ on the ROSE and no EUS was conducted. In the 9 cases in which ROSE was not available and the 20 cases with negative ROSE, EUS was carried out after the EBUS staging (64.4\%). The presence or absence of ROSE did not affect the final diagnostic yield of the test $(p=0.8637)$. The agreement between the results from ROSE and the final EBUS and EUS diagnosis was 76\% (kappa 0.52; 95\% CI: 0.193-0.851), which represents substantial agreement.

All patients without $\mathrm{N} 2-\mathrm{N} 3$ involvement in EBUS and EUS underwent surgery except for one, who underwent mediastinoscopy. In total, 139 punctures were performed on lymph nodes with an average size of $8.81 \pm 3.38 \mathrm{~mm}$ and an average maximum SUV of $1.17 \pm 2.90$. The most commonly sampled stations were 7 and $4 \mathrm{R}$ (shown in Fig. 2). The number of punctures per patient was $3.33 \pm$ 1.40 .

No severe complications were registered in any of the procedures. Mild desaturation was observed in 7 patients: 3 who only underwent EBUS and 4 in which the combined test was performed. No statistical differences were observed regarding complications between the procedure with EBUS alone and the combined EBUS and EUS test $(p=0.441)$.

One hundred and seven EBUS punctures were performed in 45 patients, and a valid sample was obtained in $93.4 \%$ of the cases. Out of these 45 patients, 16 were positive $(35.5 \%)$ and 11 of them had N2-N3 involvement (24.4\%). In addition, 4 patients were FNs (8.8\%), 3 of them in the central tumor group, and 1 in the N1 involve-
Cordovilla et al. 
Fig. 1. Flow chart. Selection of the patients.

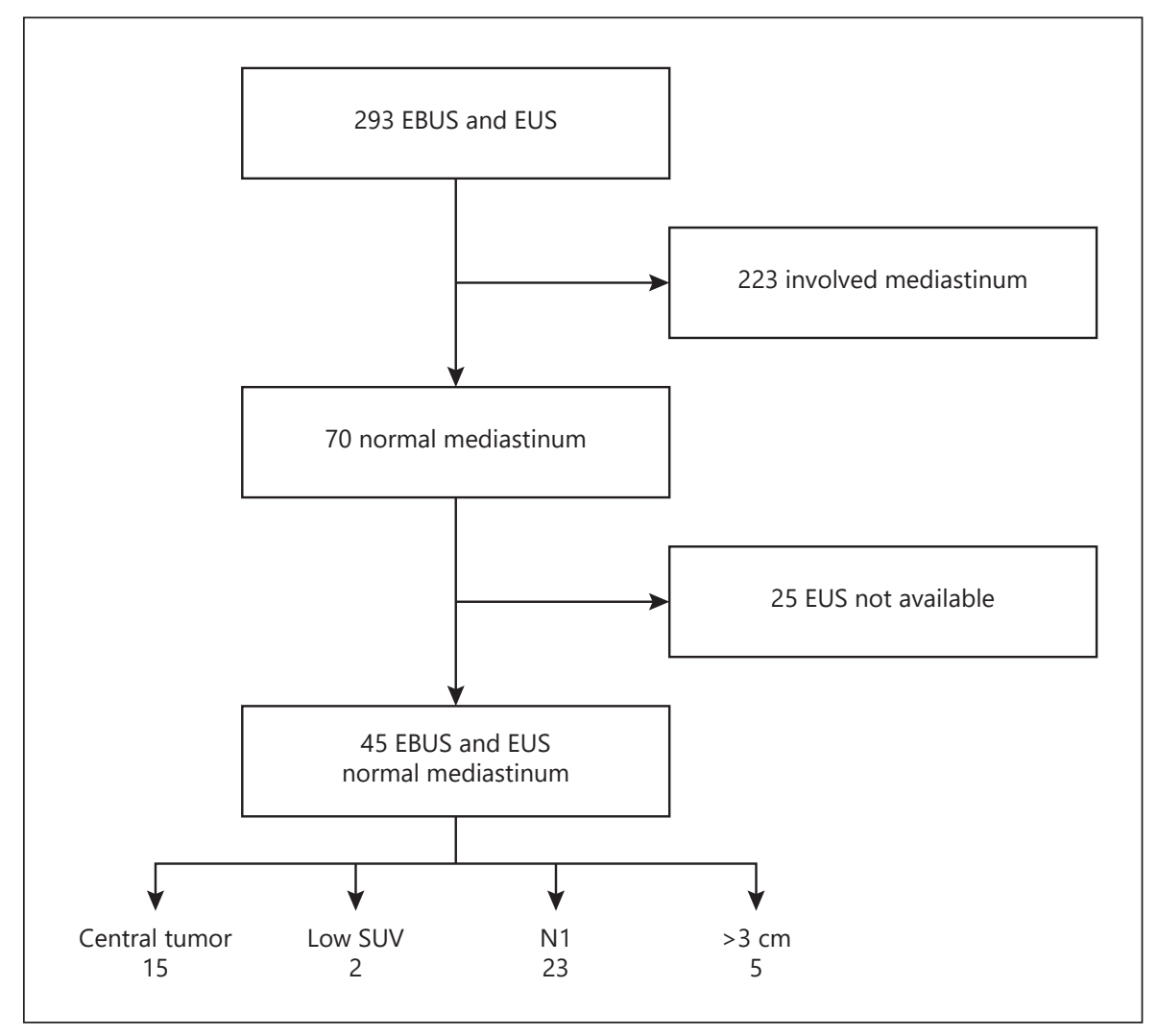

Table 1. General demographics of the 45 patients

\begin{tabular}{ll}
\hline Sex, $n(\%)$ & \\
Male & $39(86.7)$ \\
Female & $6(13.3)$ \\
Median age & $67.9 \pm 8.7$ years \\
Tumor localization, $n(\%)$ & \\
$\quad$ Right & $26(57.8)$ \\
Left & $19(42.2)$ \\
Type of normal mediastinum, $n(\%)$ & $15(33.3)$ \\
Central tumor & $23(51.1)$ \\
N1 involvement & $5(11.1)$ \\
$>3$ cm & $2(4.5)$ \\
Low SUV & \\
\hline SUV, standardized uptake value. & \\
\hline
\end{tabular}

ment group. In 3 of those cases, the involved stations were accessible with EBUS (Table 2).

Regarding EUS, 32 punctures were performed in 29 patients $(64.4 \%)$, with a valid sample in $81.2 \%$ of the cases and 3 positive results (6.6\%). In these patients, the diagnosis was obtained with this test alone, and it led to a change in the staging (Table 2). In 2 cases, the stations punctured with EBUS were negative or not valid; however, station 7 was positive with EUS. Both patients moved from N0 to N1 involvement to N2. In the other patient, station $4 \mathrm{R}$ was negative in EBUS and station 7 was not valid. In the EUS, station 9 was positive. These diagnoses obtained exclusively with EUS led to an increase in $S$ by $15 \%$ and in the accuracy of the test by $6.6 \%$ (Table 3 ).

With the combined EBUS and EUS tests, 139 punctures were performed, with a valid sample in $90.5 \%$ of the cases. In all the patients, a valid sample was obtained in some of the stations analyzed. Out of the 45 patients, 19 were positive with EBUS and EUS (42.2\%), 5 of whom were N1 (26.3\%), 11 were N2 (57.9\%), and 3 were N3 (15.8\%). Therefore, the rate of N2-N3 cases detected by EBUS and EUS was $31.1 \%$ (14 patients). There was only $1 \mathrm{FN}(2.2 \%)$ who was detected after surgery and presented micrometastasis of squamous cell carcinoma in station 4R. The number of combined EBUS and EUS tests required to reduce FN results by 1 (NNT) was 33 , and the ARR for FNs was 3\%.

The final prevalence of the metastatic disease at any stage $\mathrm{N}$ was $44.4 \%$, and in the case of $\mathrm{N} 2-\mathrm{N} 3$ involvement, it was $33.3 \%$. N2-N3 prevalence was higher in the group of patients with a central tumor ( 6 cases, $40 \%$ ), with 
Fig. 2. Region stations punctured by EBUS and EUS. 7p, station 7 punctured with EUS; 4Lp, station 4L punctured with EUS; TC, lymph node in celiac trunk; Supra, left suprarenal gland; EBUS, endobronchial ultrasound; EUS, endoscopic ultrasound.

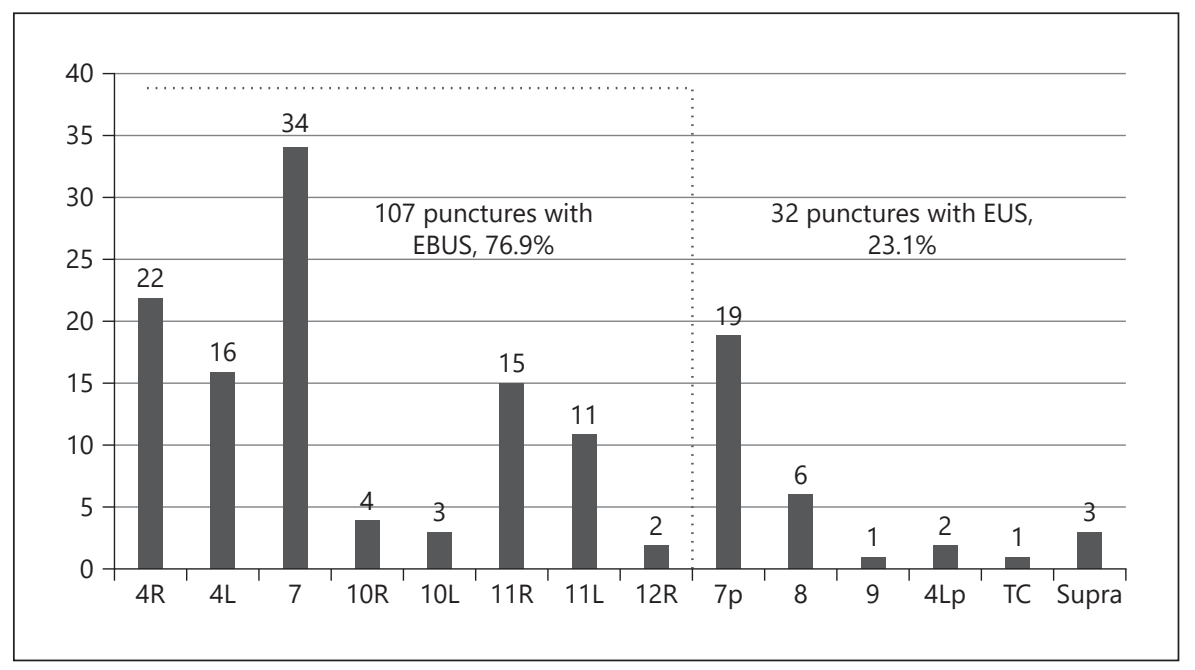

Table 2. FNs with EBUS and EUS and exclusive diagnoses with EUS

\begin{tabular}{|c|c|c|c|c|c|c|c|}
\hline Central tumor & 4R-, 4L-,7- & $4 \mathrm{~L}-, 7-$ & $4 \mathrm{R}$ & No & No & $\mathrm{N} 2$ & $\begin{array}{l}\text { Micrometastasis in } 4 \mathrm{R} \text { in } \\
\text { surgery }\end{array}$ \\
\hline Central tumor & $4 \mathrm{R}-, 4 \mathrm{Lnv}, 7 \mathrm{nv}$ & $7+, 4 \mathrm{~L}-$ & 7 & Yes & No & N2 & $+\ln 7$ with EUS \\
\hline Central tumor & $7-$ & $7+, \mathrm{TC}-$ & 7 & Yes & No & $\mathrm{N} 2$ & $+\ln 7$ with EUS \\
\hline N1 & $4 \mathrm{R}-, 7 \mathrm{nv}$ & $9+, 7-$ & 9 & Yes & NO & N2 & 9+, not accessible with EBUS \\
\hline
\end{tabular}

nv, nonvalid sample; TC, celiac trunk; FNs, false negatives; EBUS, endobronchial ultrasound; EUS, endoscopic ultrasound.

Table 3. Improvement in statistical values

\begin{tabular}{llllll}
\hline & S, \% & NPV, \% & Accuracy, $\%$ & Positive patients & -LR \\
\hline EBUS & $80(59.9-100)$ & $86.2(71.9-100)$ & $91.1(81.7-100)$ & 16 & $0.20(0.08-0.48)$ \\
EBUS and EUS & $95(82.9-100)$ & $96.1(86.8-100)$ & $97.8(92.4-100)$ & 19 & 13.8 \\
Variation & +15 & +9.9 & +6.6 & +3 & -0.15 \\
\hline
\end{tabular}

NPV, negative predictive value; -LR, negative likelihood ratio; Pp, post-test probability; S, sensitivity; EBUS, endobronchial ultrasound; EUS, endoscopic ultrasound.

5 positive cases for $\mathrm{N} 2$ and 1 for $\mathrm{N} 3$, followed by patients with suspicion of $\mathrm{N} 1$ involvement ( 8 cases, $34.8 \%$ ), with 6 positive cases for $\mathrm{N} 2$ and 2 for $\mathrm{N} 3$. In the rest of groups with a radiologically normal mediastinum, there were no positive cases with $\mathrm{N} 2-\mathrm{N} 3$ involvement.

EBUS was used to diagnose correctly $91.11 \%$ of the patients (95\% CI: $81.69-100 \%)$, with a S of $80 \%$ (95\% CI: 59.97-100\%), a NPV of $86.21 \%$ (95\% CI: 71.93-100\%), and a -LR of 0.20 (Table 4 ). The post-test probability rep- resented with Fagan nomograms was 13.8\% (Fig. 3). When EUS was added, a correct diagnosis was reached for 97.78\% of the patients (95\% CI: 92.36-100\%), with S: $95 \%$ (95\% CI: 82.95-100\%), VPN: 96.15\% (95\% CI: 96.84$100 \%$ ), and -LR: 0.05 (Table 3). The post-test probability represented with Fagan nomograms was 3.8\% (shown in Fig. 3). In summary, the combined EBUS and EUS tests in patients with a radiologically normal mediastinum represent an increase in S (15\%), the validity index (6.6\%), 


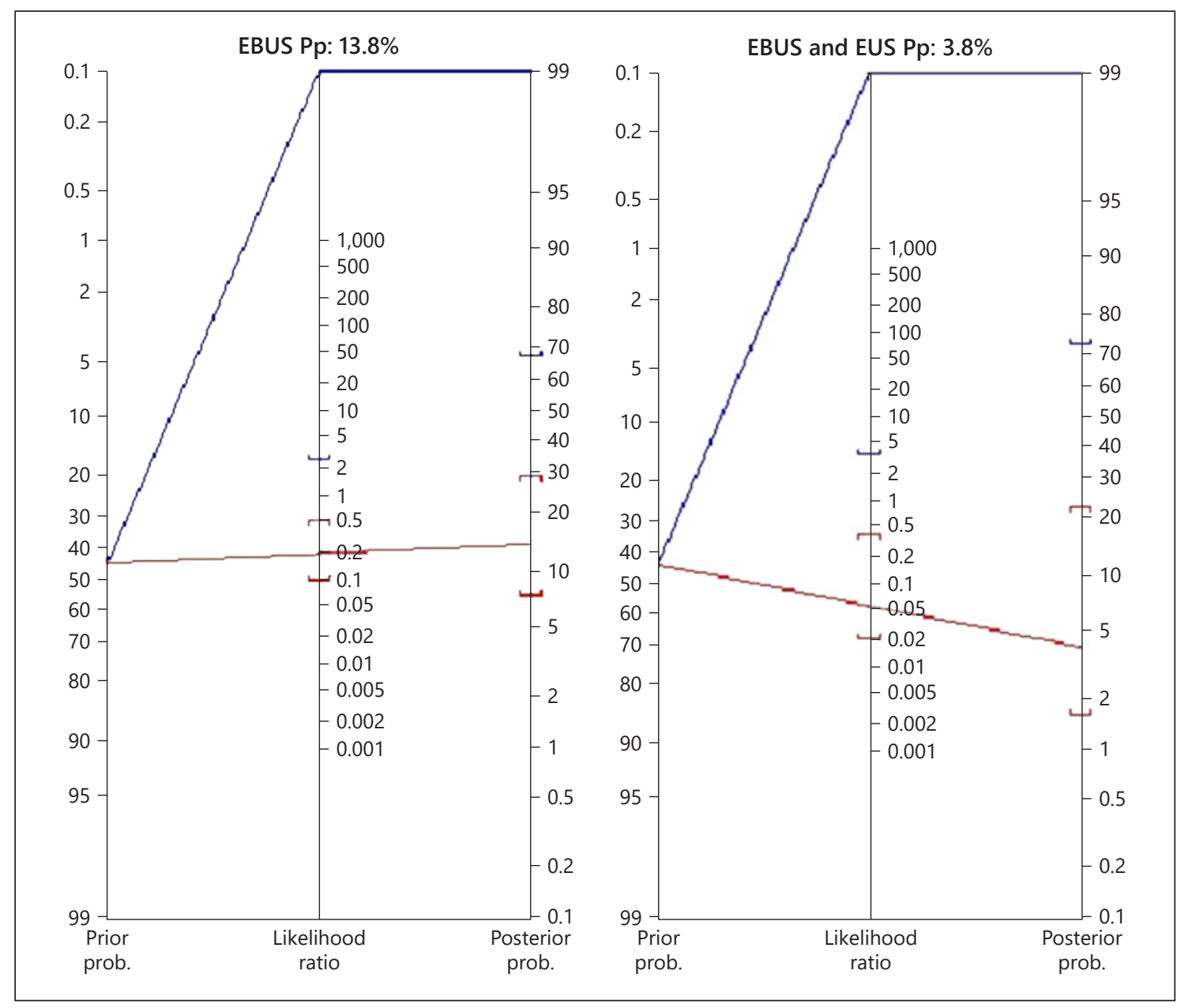

Fig. 3. Fagan nomograms in EBUS and EBUS-EUS. Pp, post-test probability; EBUS, endobronchial ultrasound; EUS, endoscopic ultrasound.

and NPV (9.9\%) when compared with EBUS alone, which significantly increases the probability to achieve the correct diagnosis (Table 3 ).

\section{Discussion}

This study shows that the systematic use of the combined EBUS and EUS tests in the staging of patients with NSCLC and a radiologically normal mediastinum increases the $\mathrm{S}$ to detect occult metastasis by up to $15.4 \%$ (92.3\% vs. $76.9 \%$ ) when compared with EBUS alone. This increase in $S$ had already been observed in other studies, as it has been published in several meta-analyses, such as those by Dhooria et al. [11] and Korevaar et al. [13], who report an improvement by $11 \%$ and $12 \%$, respectively. More recently, Crombag et al. [24] observed an improve-
Table 4. Precision statistics of EBUS and EBUS-EUS

\begin{tabular}{lll}
\hline & $\begin{array}{l}\text { EBUS, \% } \\
(95 \% \mathrm{Cl})\end{array}$ & $\begin{array}{l}\text { EBUS and EUS, \% } \\
(95 \% \mathrm{Cl})\end{array}$ \\
\hline Sensitivity & $80(59.97-100)$ & $95(82.95-100)$ \\
Specificity & $100(98-100)$ & $100(98-100)$ \\
Validity index & $91.11(81.69-100)$ & $97.78(92.36-100)$ \\
PPV & $100(96.88-100)$ & $100(97.37-100)$ \\
NPV & $86.21(71.93-100)$ & $96.15(86.84-100)$ \\
YI & $0.80(0.62-0.98)$ & $0.95(0.85-0.01)$ \\
-LR & $0.20(0.08-0.48)$ & $0.05(0.01-0.34)$ \\
Pp & 13.8 & 3.8 \\
Prevalence of N2-N3 & 24.4 & 31.1
\end{tabular}

$\mathrm{Cl}$, confidence interval; $-\mathrm{LR}$, negative likelihood ratio; PPV, positive predictive value; NPV, negative predictive value; EBUS, endobronchial ultrasound; EUS, endoscopic ultrasound; YI, Youden's index; Pp, post-test probability. 
ment by $9 \%$ when performing EBUS and EUS-b systematically in staging. However, these studies include patients with mediastinal involvement in the imaging tests (PET-CT), and they do not establish a difference with patients without mediastinal involvement. Only 2 metaanalyses have been published that analyze the influence of EBUS on the staging of this type of patients. One of those studies analyzes the influence of EBUS as a single procedure [30]. The second one, published by Leong et al. [14], includes 13 studies, but only 3 of them analyze the influence of the combined EBUS and EUS tests [19,21]. Based on those studies, the $S$ of the combined test was $71 \%$, compared to $52 \%$ for EBUS alone, which represents an increase in S by $19 \%$. Therefore, staging with combined EBUS and EUS in patients with a radiologically normal mediastinum is the most adequate option because it can diagnose $4.9 \%$ more cases.

These data are similar to those found in our study, in which $6.6 \%$ more cases were diagnosed, $24.4 \%$ of which changed from $\mathrm{N} 0$ to $\mathrm{N} 2 ; 6.6 \%$ changed to $\mathrm{N} 3$; and $11.1 \%$ changed from N0 to N1. All these results are clinically relevant, which supports the utility of this type of staging. In that meta-analysis [14], the calculated NNT for the combined test compared with EBUS alone was 21 procedures, which is slightly lower than what we observed in our study, with an NNT of 33, with an ARR of 3\%. This analysis is also shown in the study by Korevaar et al. [13], in which 25 combined procedures are required to reduce 1 FN result although the series includes patients with mediastinal involvement in the imaging tests. It could seem that this is a high number, but we need to consider that the clinical benefit is large, since lung cancer is a serious condition. In addition, correct staging prevents unnecessary thoracotomies and unwanted secondary effects and it reduces health costs [31]. On the other hand, adding EUS to the EBUS procedure does not involve an increase in complications, which means that the cost-benefit is ultimately positive [32].

In our center, EUS was decided, instead of EUS-b, due to the lack of training of the interventional pneumologist. It is necessary to highlight that there is no specific training for this procedure in Spain, as well as in other countries, which accounts for the lack of adherence of endoscopists to the staging guidelines $[33,34]$. On the other hand, the studies show that both the combined EBUS and EUS strategies and the EBUS and EUS-b procedures are valid options for staging. Although some authors have reported higher $S$ values with the first one ( $87 \%$ vs. $84 \%$ ) [15], and others with the second one ( $85 \%$ vs. $88 \%$ ) [12], the results are similar for both approaches.
In both cases, the test is performed at the same time, which means that the patient is only subject to one procedure. EUS has some advantages over EUS-b, such as better visualization or a better access for punctures. Its main disadvantage, apart from the costs derived from the use of 2 endoscopes and 2 explorers, is the lack of availability to perform the test as a single procedure together with EBUS, in order to spare patients from undergoing 2 examinations and from everything these involve. In our series, the gastrointestinal specialist was not available in up to $35 \%$ of the cases. Therefore, we believe that the interventional pulmonologist must receive training in EUS-b and incorporate this technique in combined staging procedures [35]. In fact, considering these results, EBUS and EUS-b are performed systematically to all patients in our center.

Apart from the improvement in S, we observed an improvement in the global yield of the test, as well as in VPN and $-\mathrm{LR}$. This improvement was due to the fact that the combined test was able to detect more cases of metastatic involvement than EBUS alone. A decrease in FN results was also observed (from 4 cases in EBUS alone to 1 case in EBUS and EUS), which were in almost all cases found in regions that could be accessed with EBUS, as has been described by other authors $[26,36]$. The only case that was not detected in the combined procedure was due to the presence of micrometastasis, which cannot be detected by any of these tests. We must highlight the fact that puncturing the same region shows a good diagnostic yield, which may be explained by the nonuniform presence of metastasis in the lymph node, as has been described in other studies [19,37]. This problem could be solved with other techniques such as EBUS elastography [38]. Only one case was found in a station that could not be accessed with EBUS (station 9). It is necessary to point out that the use of EUS in these patients did not only lead to a correct diagnosis but was the only method that could provide it, so that diagnosis and staging were obtained in a single procedure, thus preventing unnecessary procedures and complications, as some authors recommend [39]. However, there is controversy on the need to use this combined strategy in patients with a normal mediastinum because the rate of mediastinal involvement in stations that are not accessible with EBUS ( 8 and 9) without an involvement of upper mediastinal stations is low [40, 41]. This was also observed in our series and, in spite of it, $S$ increased when EUS was added.

The decision to start with EBUS and continue with EUS if the first test was negative is supported by studies that show a significant increase in $S$ and significant staging changes when this strategy is implemented, rather
98

Biomed Hub 2021;6:92-101 DOI: $10.1159 / 000519034$
Cordovilla et al. 
than starting with EUS and continuing with EBUS because this second strategy has no impact on $S$ and does not have much influence on staging changes [28].

With regard to the rate of metastatic mediastinal involvement in patients with a radiologically normal mediastinum, the studies published in the literature show figures that range between $20 \%$ and $42 \%$, with a rate of $21 \%$ for patients with central tumors and $30 \%$ for patients with radiological N1 tumors, which makes it advisable to perform EBUS [17, 19, 41-44]. In our series, we also observed similar rates of metastatic mediastinal involvement, which supports the need to apply invasive techniques for the staging of this type of patients in our hospitals. It is true that the prevalence of metastatic disease in our series is higher in the group with central tumors and tumors with $\mathrm{N} 1$ involvement than in other series. However, we must highlight that, in our study, the procedure is systematic and detailed, as other authors recommend [16], which means that all the accessible stations were explored with both procedures and all the lymph nodes larger than $5 \mathrm{~mm}$ were punctured. We do not know how thorough the procedure was in other published series with a lower prevalence, since the procedure is not explained in detail, which is also reflected in their interobserver variability [34, 45]. On the other hand, the lack of consensus for the definition of central tumors also explains the variability in the rate of metastatic involvement [46].

In our series, these data also confirm that the diagnostic yield of EBUS and EUS is clearly higher than EUS alone ( $97 \%$ vs. $91.4 \%$ ), with a NPV that rises from $88 \%$ to $95.6 \%$ and a decrease in -LR from 0.20 to 0.05 . This increase in the diagnostic yield had already been observed by other authors [19] in this type of patients with a radiologically normal mediastinum, with similar results to what was found in our series (NPV: $86 \%$ vs. $91 \%$ ). This author advises against confirmation mediastinoscopy although the procedure is recommended by the other authors [14].

Therefore, if the puncture tests are negative, mediastinoscopy is recommended if the post-test probability of malignancy is $>10 \%$ [6]. In our series, the post-test probability was $3.8 \%$. Consequently, no confirmation mediastinoscopy was performed. However, in the cases in which the staging could not be completed, we recommend mediastinoscopy prior to surgery because the post-test probability in these cases is $13.8 \%$, which is higher than what is established in the literature [6]. According to the data in our study, confirmation mediastinoscopy is not necessary when staging is performed with combined EBUS and EUS, as other authors have pointed out $[18,47,48]$.

Lung Cancer Staging by EBUS-EUS in Normal Mediastinum
We must mention some limitations in our study since it is a single-center analysis in which the endoscopists and the bronchoscopists had a vast experience with the procedure. Thus, the results may not be extrapolated to other centers. The number of patients studied is also small yet these data stand well with the similar past studies. On the other hand, in a significant number of patients, EUS was not available thus reducing the total number of analyzed patients. For this reason, it is important that interventional pulmonologist receive training with this technique.

\section{Conclusions}

In patients with NSCLC and a radiologically normal mediastinum, a systematic and combined staging strategy with EBUS and EUS leads to increased sensitivity in the detection of mediastinal metastases compared with EBUS alone, which may justify their routine use. The high accuracy of the test means that mediastinoscopy is not required to confirm the results in these patients. Moreover, the combined technique has an added clinical value because some patients are diagnosed exclusively with EUS. The combined strategy of EBUS and EUS with a multidisciplinary approach is useful and effective in the staging of NSCLC but since the availability of EUS is low, we recommend that interventional pulmonologists receive training with EUS-b.

\section{Acknowledgements}

Foremost, the authors would like to express their gratitude to their service coordinator, Prof. Miguel Barrueco Ferrero PhD, Professor at the Faculty of Medicine, Salamanca University and Pulmonary Department of the Salamanca University Hospital chief, for his support and guidance throughout this research. Also, we are grateful to Prof. María Dolores Ludeña de la Cruz PhD, Professor at the Faculty of Medicine, Salamanca University, for her priceless help and advice. Last, but not the least, we would like to thank all our teammates in the Interventional Pulmonology Unit of the Salamanca University Hospital: Manuel, Verónica, Javier, Francisco, María José, and Mercedes and all the people who, with their daily work, made this study possible.

\section{Statement of Ethics}

All patients signed a written informed consent and the research was approved by ethical board of the Salamanca University Hospital (no.: 27032016). Published research comply with internationally accepted standards for research practice and reporting.

Biomed Hub 2021;6:92-101 


\section{Conflict of Interest Statement}

The authors have no conflicts of interest to declare.

\section{Funding Sources}

No external sources were required to carry out this study.

\section{Author Contributions}

Rosa Cordovilla contributed to the design of the work, acquisition the samples by EBUS, analysis and interpretation of data for the work, drafting the work, redaction the manuscript, and revision of the manuscript. Marco López-Zubizarreta and Miguel Igle- sias contributed to acquisition of samples by EBUS, analysis and interpretation of data for the work, and revision of the manuscript. Antonio Velasco and Alberto Álvarez contributed to acquisition of samples by EUS and revision of the manuscript. Marta Rodríguez and Asunción Gómez contributed to analysis of samples and revision of the manuscript. Miguel Ángel Hernández-Mezquita contributed to inclusion of patients, drafting the work, and revision of the manuscript.

\section{Data Availability Statement}

All data that support the findings of this research are not available on internet due to the current legal framework in Spain (LOPDGDD 3/2018, ref: BOE-A-2018-16673). Further enquires can be directed to the corresponding author.

\section{References}

1 Sanz-Santos J, Call Caja S. Preoperative staging of the mediastinum is an essential and multidisciplinary task. Respirology. 2020;25 Suppl 2:37-48.

2 Silvestri GA, Gonzalez AV, Jantz MA, Margolis ML, Gould MK, Tanoue LT, et al. Methods for staging non-small cell lung cancer: diagnosis and management of lung cancer, 3rd ed: American College of Chest Physicians evidence-based clinical practice guidelines. Chest. 2013;143(5):e211S-50S.

3 Rusch VW, Asamura H, Watanabe H, Giroux DJ, Rami-Porta R, Goldstraw P. The IASLC lung cancer staging project: a proposal for a new international lymph node map in the forthcoming seventh edition of the TNM classification for lung cancer. J Thorac Oncol. 2009;4(5):568-77.

4 Vilmann P, Clementsen PF, Colella S, Siemsen M, De Leyn P, Dumonceau JM, et al. Combined endobronchial and oesophageal endosonography for the diagnosis and staging of lung cancer. European Society of Gastrointestinal Endoscopy (ESGE) Guideline, in cooperation with the European Respiratory Society (ERS) and the European Society of Thoracic Surgeons (ESTS). Eur Respir J. 2015;46(1):40.

5 Sánchez de Cos J, Hernández Hernández J, Jiménez López MF, Padrones Sánchez S, Rosell Gratacós A, Rami Porta R. Normativa SEPAR sobre estadificación del cáncer de pulmón. Arch Bronconeumol. 2011;47(9):454-65.

6 De Leyn P, Dooms C, Kuzdzal J, Lardinois D, Passlick B, Rami-Porta R, et al. Revised ESTS guidelines for preoperative mediastinal lymph node staging for non-small-cell lung cancer. Eur J Cardiothorac Surg. 2014;45(5): 787-98.

7 Beyaz F, Verhoeven RLJ, Schuurbiers OCJ, Verhagen AFTM, van der Heijden EHFM. Occult lymph node metastases in clinical No/ N1 NSCLC; a single center in-depth analysis. Lung Cancer. 2020 Dec;150:186-94.
8 DuComb EA, Tonelli BA, Tuo Y, Cole BF, Mori $\mathrm{V}$, Bates JHT, et al. Evidence for expanding invasive mediastinal staging for peripheral $\mathrm{T} 1$ lung tumors. Chest. 2020 Nov; 158(5):2192-9.

9 Resio BJ, Canavan M, Mase V, Dhanasopon AP, Blasberg JD, Boffa DJ. Invasive staging procedures do not prevent nodal metastases from being missed in stage I lung cancer. Ann Thorac Surg. 2020 Aug;110(2):390-7.

10 Zhang R, Ying K, Shi L, Zhang L, Zhou L. Combined endobronchial and endoscopic ultrasound-guided fine needle aspiration for mediastinal lymph node staging of lung cancer: a meta-analysis. Eur J Cancer. 2013;49(8): $1860-7$.

11 Dhooria S, Aggarwal AN, Gupta D, Behera D, Agarwal R. Utility and safety of endoscopic ultrasound with bronchoscope-guided fineneedle aspiration in mediastinal lymph node sampling: systematic review and meta-analysis. Respir Care. 2015;60(7):1040.

12 Labarca G, Aravena C, Ortega F, Arenas A, Majid A, Folch E, et al. Minimally invasive methods for staging in lung cancer: systematic review and meta-analysis. Pulm Med. 2016;2016:1024709. Epub 2016 Oct 13.

13 Korevaar DA, Crombag LM, Cohen JF, Spijker R, Bossuyt PM, Annema JT. Added value of combined endobronchial and oesophageal endosonography for mediastinal nodal staging in lung cancer: a systematic review and meta-analysis. Lancet Respir Med. 2016; 4(12):960-8.

14 Leong TL, Loveland PM, Gorelik A, Irving L, Steinfort DP. Preoperative staging by EBUS in cN0/N1 lung cancer: systematic review and meta-analysis. J Bronchology Interv Pulmonol. 2019;26(3): 155

15 Shen Y, Qin S, Jiang H. Endobronchial ultrasound-guided transbronchial needle aspiration combined with either endoscopic ultrasound-guided fine-needle aspiration or endoscopic ultrasound using the EBUS scope-guided fine-needle aspiration for diagnosing and staging mediastinal diseases: a systematic review and meta-analysis. Clinics. 2020;75:e1759.

16 Detterbeck F, Puchalski J, Rubinowitz A, Cheng D. Classification of the thoroughness of mediastinal staging of lung cancer. Chest. 2010;137(2):436-42.

17 Dooms C, Tournoy KG, Schuurbiers O, Decaluwe H, De Ryck F, Verhagen A, et al. Endosonography for mediastinal nodal staging of clinical N1 non-small cell lung cancer: a prospective multicenter study. Chest. 2015; 147(1):209-15.

18 Murgu SD. Diagnosing and staging lung cancer involving the mediastinum. Chest. 2015; 147(5):1401-12.

19 Szlubowski A, Zieliński M, Soja J, Annema JT, Sośnicki W, Jakubiak M, et al. A combined approach of endobronchial and endoscopic ultrasound-guided needle aspiration in the radiologically normal mediastinum in nonsmall-cell lung cancer staging - a prospective trial. Eur J Cardiothorac Surg. 2010;37(5): 1175-9.

20 Herth FJF, Krasnik M, Kahn N, Eberhardt R, Ernst A. Combined endoscopic-endobronchial ultrasound-guided fine-needle aspiration of mediastinal lymph nodes through a single bronchoscope in 150 patients with suspected lung cancer. Chest. 2010;138(4):790-4.

21 Oki M, Saka H, Ando M, Kitagawa C, Kogure Y, Seki Y. Endoscopic ultrasound-guided fine needle aspiration and endobronchial ultrasound-guided transbronchial needle aspiration: are two better than one in mediastinal staging of non-small cell lung cancer? J Thorac Cardiovasc Surg. 2014 Oct 1;148(4):116977.

22 Mehta AC, Cicenia J, Yasufuku K. The chef has a knife...: endoscopic ultrasound-guided fine-needle aspiration by a pulmonologist. Chest. 2015;147(5):1201-3. 
23 Sanz-Santos J, Serra P, Torky M, Andreo F, Centeno C, Mendiluce L, et al. Systematic compared with targeted staging with endobronchial ultrasound in patients with lung cancer. Ann Thorac Surg. 2018;106(2):398403.

24 Crombag LMM, Dooms C, Stigt JA, Tournoy KG, Schuurbiers OCJ, Ninaber MK, et al. Systematic and combined endosonographic staging of lung cancer (SCORE study). Eur Respir J. 2019;53(2):1800800.

25 Ong P, Grosu H, Eapen GA, Rodriguez M, Lazarus D, Ost D, et al. Endobronchial ultrasound-guided transbronchial needle aspiration for systematic nodal staging of lung cancer in patients with N0 disease by computed tomography and integrated positron emission tomography-computed tomography. Ann Am Thorac Soc. 2015;12(3):415-9.

26 Sanz-Santos J, Serra M, Gallego M, Montón C, Cosio B, Sauleda J, et al. Determinants of false-negative results in non-small-cell lung cancer staging by endobronchial ultrasoundguided needle aspiration. Eur J Cardiothorac Surg. 2015;47(4):642-7.

27 Kang HJ, Hwangbo B, Lee GK, Nam BH, Lee HS, Kim MS, et al. EBUS-centred versus EUScentred mediastinal staging in lung cancer: a randomised controlled trial. Thorax. 2014; 69(3):261.

28 Pak K, Park S, Cheon GJ, Kang KW, Kim IJ, Lee DS, et al. Update on nodal staging in nonsmall cell lung cancer with integrated positron emission tomography/computed tomography: a meta-analysis. Ann Nucl Med. 2015;29(5):409-19.

29 Um SW, Kim HK, Jung SH, Han J, Lee KJ, Park HY, et al. Endobronchial ultrasound versus mediastinoscopy for mediastinal nodal staging of non-small-cell lung cancer. J Thorac Oncol. 2015;10(2):331-7.

30 El-Osta H, Jani P, Mansour A, Rascoe P, Jafri $S$. Endobronchial ultrasound for nodal staging of patients with non-small-cell lung cancer with radiologically normal mediastinum. A meta-analysis. Ann Am Thorac Soc. 2018 Apr 23;15(7):864-74.
31 Turna A. ESTS staging guidelines for nonsmall cell lung cancer: a good guide to best ever accuracy and high survival rate. J Thorac Dis. 2018;10(8):E661-3.

32 von Bartheld MB, van Breda A, Annema JT. Complication rate of endosonography (endobronchial and endoscopic ultrasound): a systematic review. Respiration. 2014;87(4):34351.

33 Bousema JE, van Dorp M, Hoeijmakers F, Huijbregts IA, Barlo NP, Bootsma GP, et al. Guideline adherence of mediastinal staging of non-small cell lung cancer: a multicentre retrospective analysis. Lung Cancer. 2019;134: $52-8$.

34 Guinde J, Roy P, Dutau H, Musani A, Quadrelli S, Stratakos G, et al. An international survey of mediastinal staging practices amongst interventional bronchoscopists. Respiration. 2020;99(6):508-15.

35 Bugalho A, de Santis M, Szlubowski A, Rozman A, Eberhardt R. Trans-esophageal endobronchial ultrasound-guided needle aspiration (EUS-B-NA): a road map for the chest physician. Pulmonology. 2018;24(1):32-41.

36 Shin SH, Jeong B-H, Jhun BW, Yoo H, Lee K, $\mathrm{Kim} \mathrm{H}$, et al. The utility of endosonography for mediastinal staging of non-small cell lung cancer in patients with radiological N0 disease. Lung Cancer. 2020 Jan 1;139:151-6.

37 Tournoy KG, Annema JT, Krasnik M, Herth FJ, van Meerbeeck JP. Endoscopic and endobronchial ultrasonography according to the proposed lymph node map definition in the seventh edition of the tumor, node, metastasis classification for lung cancer. J Thorac Oncol. 2009;4(12):1576-84.

38 Andreo García F, Centeno Clemente CÁ, Sanz Santos J, Barturen Barroso Á, Hernández Gallego A, Ruiz Manzano J. Experiencia inicial con elastografía en tiempo real mediante ecobroncoscopio en la evaluación de ganglios linfáticos mediastínicos. Arch Bronconeumol. 2015;51(2):e8-11.

39 Ost DE, Niu J, Zhao H, Grosu HB, Giordano $\mathrm{SH}$. Quality gaps and comparative effectiveness in lung cancer staging and diagnosis. Chest. 2020;157(5):1322-45.
40 Obiols C, Call S, Rami-Porta R, Trujillo-Reyes JC, Saumench R, Iglesias M, et al. Survival of patients with unsuspected $\mathrm{pN} 2$ non-small cell lung cancer after an accurate preoperative mediastinal staging. Ann Thorac Surg. 2014; 97(3):957-64.

41 Herth FJF, Eberhardt R, Krasnik M, Ernst A. Endobronchial ultrasound-guided transbronchial needle aspiration of lymph nodes in the radiologically and positron emission tomography-normal mediastinum in patients with lung cancer. Chest. 2008;133(4):887-91.

42 Lee PC, Port JL, Korst RJ, Liss Y, Meherally DN, Altorki NK. Risk factors for occult mediastinal metastases in clinical stage I non-small cell lung cancer. Ann Thorac Surg. 2007; 84(1):177-81.

43 Yasufuku K, Nakajima T, Waddell T, Keshavjee S, Yoshino I. Endobronchial ultrasound-guided transbronchial needle aspiration for differentiating N0 versus N1 lung cancer. Ann Thorac Surg. 2013 Nov 1;96(5): 1756-60.

44 Decaluwé H, Dooms C, D’Journo XB, Call S, Sanchez D, Haager B, et al. Mediastinal staging by videomediastinoscopy in clinical N1 nonsmall cell lung cancer: a prospective multicentre study. Eur Respir J. 2017;50(6):1701493.

45 Miller RJ, Mudambi L, Vial MR, Hernandez M, Eapen GA. Evaluation of appropriate mediastinal staging among endobronchial ultrasound bronchoscopists. Ann Am Thorac Soc. 2017;14(7):1162-8

46 Aigner C. To be or not to be central-does this really matter? Eur J Cardiothorac Surg. 2018; 54(1):141.

47 Tournoy KG, Keller SM, Annema JT. Mediastinal staging of lung cancer: novel concepts. Lancet Oncol. 2012;13(5):e221-9.

48 Bousema JE, Dijkgraaf MGW, Papen-Botterhuis NE, Schreurs HW, Maessen JG, van der Heijden EH, et al. MEDIASTinal staging of non-small cell lung cancer by endobronchial and endoscopic ultrasonography with or without additional surgical mediastinoscopy (MEDIASTrial): study protocol of a multicenter randomised controlled trial. $\mathrm{BMC}$ Surg. 2018;18(1):27. 